\title{
A CONTRIBUIÇÃO DAS PRÁTICAS SUSTENTÁVEIS NA LOGÍSTICA HUMANITÁRIA EM CATÁSTROFES AMBIENTAIS NO DIREITO AMBIENTAL INTERNACIONAL
}

\author{
THE CONTRIBUTION OF GREEN PRACTICES IN HUMANITARIAN LOGISTICS \\ ON DISASTERS IN THE INTERNATIONAL ENVIRONMENTAL LAW
}

\section{Julia Farah Scholz}

Mestranda em Direito pela Universidade Federal de Santa Catarina (Florianópolis/Brasil).

Bolsista pela CAPES. Membra do grupo de estudos em História da Cultura Jurídica "Ius commune"

na Universidade Federal de Santa Catarina (Florianópolis/Brasil).

juliafarahscholz@gmail.com

\section{Alexandre Augusto Karl}

Mestrando em Engenharia de Produção pela Universidade Federal de Santa Catarina (Florianópolis, Brasil). Bolsista pela CAPES. Membro do Laboratório de Gestão e Avaliação Ambiental (LGAA) na Universidade Federal de Santa Catarina (UFSC).

E-mail: alexandreaugustokarl@gmail.com 


\section{RESUMO}

Todo ser humano está vulnerável a presenciar e/ou viver um desastre, sendo ele ocasionado pelo homem ou pela força da natureza. Em consequência, os desastres requerem provisões emergenciais para auxiliar as pessoas, levando em consideração as diversas perdas ocorridas. Assim, torna-se importante compreender a logística humanitária de forma holística, assim como a gestão ambiental a ela associada. Este trabalho apresenta um panorama sobre as tendências relacionadas à logística humanitária sob a ótica sustentável, considerando assim aspectos econômicos, ambientais e ecológicos. Nessa perspectiva, o objetivo do presente artigo é analisar as contribuições da logística humanitária e práticas green na proteção internacional ao meio ambiente, a fim de concretizá-lo como um direito humano. Nesse viés, para atingir os objetivos propostos e desenvolver a presente pesquisa, foi utilizado o método indutivo, utilizando-se da pesquisa bibliográfica em livros e artigos científicos, e legislativa, com base nos instrumentos normativos internacionais relacionados ao meio ambiente, resiliência, combate à vulnerabilidades e desenvolvimento sustentável. Por conseguinte, confirmou-se a hipótese segundo a qual o desenvolvimento da logística humanitária na perspectiva sustentável e ambiental se mostra um meio eficiente de garantir a resiliência do meio ambiente saudável como um direito humano, de modo a contribuir para a concretização dos princípios e compromissos assumidos pelos países em diversos tratados e convenções internacionais.

Palavras-chave: Logística Humanitária. Práticas Sustentáveis. Direito Ambiental Internacional.

\section{ABSTRACT}

Every human being is vulnerable to witness and/or experience a disaster, whether caused by man or nature. As a result, disasters require emergency provisions to assist people, taking into account the various losses that have occurred. Thus, it is important to understand humanitarian logistics holistically as well as its associated environmental management. This paper presents an overview of trends related to humanitarian logistics in a green perspective. This paper aims to analyze the contributions of humanitarian logistics and sustainable practices in guaranteeing and protecting the environment in order to realize it as a human right. In order to achieve the proposed objectives and develop this research, the inductive method was used, using bibliographic research in books, articles from scholarly journals, and also legislative sources, based on international treatiesand protocols related to the environment, resilience, combating vulnerabilities and sustainable development. Therefore, it was confirmed the hypothesis that the development of humanitarian logistics from a sustainable and environmental perspective is an efficient mean of ensuring the resilience of the healthy environment as a human right and also to realize the principles and commitments made by countries in international treaties and protocols on the preservation of the environment and natural resources.

Keywords: Humanitarian logistics. Sustainable Practices. International Environmental Law. 


\section{INTRODUÇÃO}

Nos últimos anos, um número crescente de desastres (tanto naturais quanto provocados pelo homem) atingiu várias regiões do mundo, matando milhares de pessoas e causando milhões de vítimas indiretas. Exemplos, como o terremoto no Haiti em 2010 ou o desastre nuclear resultante no Japão em 2011, mostram a vulnerabilidade destes países a incidentes incontroláveis. De acordo com o relatório World Disaster Report, elaborado pela International Federation of Red Cross and Crescent Societies, no período 2009-2016 ocorreram mais de 771 mil mortes oriundas de desastres afetando dois bilhões de pessoas e causando danos que excederam US\$1,5 trilhão (IFRC, 2016).

O chamado Direito Internacional dos Desastres (International Disaster Law) ultrapassou a fase restrita à preocupação com o pós-desastre, passando a assumir uma postura preocupada com a gestão de riscos de desastres nas fases da prevenção, da mitigação e do preparo, rumo a uma redução no risco de desastres (BARTOLINI; NATOLI, 2018; CARVALHO, 2013). Outro ponto marcante a ser destacado sobre o Direito Internacional dos Desastres são suas interfaces e comunicações com o direito ambiental, direitos humanos, discussões relacionadas às mudanças climáticas e, ainda, com o desenvolvimento sustentável.

No caso ora em estudo, faz-se ainda necessário esclarecer as fontes de assistência pós-desastre, que são duas: o governo, com o uso de militares ou defesa civil; e as organizações internacionais de assistência, que possuem o conhecimento e recursos para ajudar as populações afetadas por essas crises (KUNZ; REINER, 2012). No entanto, na maioria das vezes, esses desastres exigem assistência internacional, dado que a maior parte da assistência humanitária é oriunda de doações.

As pesquisas em logística e gestão de práticas green tem por escopo a tomada de iniciativas ambientais que tornam organizações mais eficientes ao reduzirem o uso de recursos de diferentes maneiras possíveis. Isso porque, normalmente, na logística humanitária no pós-desastre, normalmente as respostas convencionais às vítimas dos desastres naturais perturbam o meio ambiente e todos os seres que o cercam (JILANI; ALI; KHAN, 2018).

Assim, em geral, ao se examinar as operações humanitárias em áreas críticas, pode-se afirmar que o ambiente é ainda mais danificado à medida que a maior parte das emissões de carbono atreladas às atividades logísticas se soma à saúde ambiental, já frágil, do lugar. Isso se dá ao passo que as respostas abruptas e fáceis a desastres naturais nunca são simples, envolvendo diversas variáveis a serem consideradas, como a emissão de poluentes oriunda do transporte de insumos (remédios, comida e bebida às diferentes localidades afetadas), assim como o controle do seu custo total.

Segundo Gonçalves e Lima (2018), há uma lacuna na literatura no que tange às capacidades e recursos que as organizações deveriam desenvolver, de modo a lidar com diferentes tipos e intensidades 
de desastres; estes elementos vitais à manutenção do direito ao meio ambiente ecologicamente equilibrado por meio da Logística Humanitária em catástrofes ambientais, sendo este direito humano. Nessa perspectiva, o objetivo do presente artigo é analisar as contribuições da logística humanitária e práticas green na garantia ao direito ao meio ambiente saudável, a fim de concretizá-lo como um direito humano, tomando como base os princípios e compromissos previstos na Declaração de Estocolmo, Rio e Johanesburgo, bem como de convenções e tratados internacionais relacionados à proteção ao meio ambiente, recursos naturais e direito dos desastres.

\section{LOGÍSTICA HUMANITÁRIA SOB A PERSPECTIVA GREEN EM DESASTRES}

A Logística Humanitária teve seu início na Primeira Guerra Mundial, quando o Crescente Vermelho e a Federação Internacional das Sociedades da Cruz Vermelha (IFRC) foram criados, a fim de proporcionar o auxílio necessário aos locais vulneráveis, estudando os melhores fluxos de insumos, informação e pessoas, para assim atender de forma efetiva os inúmeros possíveis desastres naturais e ocasionados pelo homem (KOVÁCS; SPENS, 2011). Assim, a tarefa básica da Logística Humanitária, utilizando a definição da International Federation of Red Cross and Red Crescent Societies "consiste em adquirir e entregar os suprimentos e serviços solicitados, nos locais e horários em que são necessários, garantindo a melhor relação custo-benefício" (IFRC, 2014, tradução nossa). No pós-desastre, esses suprimentos incluem itens vitais para a sobrevivência, tais como comida, água, abrigo temporário e remédios.

Por resposta aos danos ocasionados pela guerra nos países envolvidos no que tange às inúmeras mortes e recursos essenciais para a provisão e subsistência das requeridas nações, pôde-se notar a obrigação e inevitabilidade à Logística Humanitária, que surge para dar uma solução concreta no amparo humanitário requerido, fornecendo assistência e amparo aos feridos em combate. Deste modo, o campo da Logística Humanitária surgiu como uma resposta à destruição gerada pela guerra, e, como os países envolvidos tiveram grandes perdas no sentido de pessoas e de recursos, viu-se a necessidade de se unir forças para auxiliar os feridos em combate, bem como prover mantimentos para os hospitais e campos de prisioneiros (IFRC, 2016).

Os estudos acadêmicos em Logística Humanitária estão em fase inicial, não apresentando maturidade no contexto de quantidade de artigos, o que pode não gerar saturação e respaldo em pesquisas futuras, pesquisadores com estímulo e afinco em pesquisar sobre o tema e avançar na fronteira da pesquisa, além de conceitos, que em sua totalidade não são perfeitamente definidos; ou seja, apesar de essencial importância em se pesquisar sobre as operações humanitárias, a fim de tornar o tema algo já consolidado, a Logística Humanitária em seus estudos é relativamente nova e seus estudos incipientes (KOVÁCS; SPENS, 
2007). Ao se analisar a Logística Humanitária (LH) com a Logística Empresarial (LE), ou logística clássica, utilizada no mundo todo nas organizações empresariais, as duas antigamente eram negligenciadas nos setores em que atuam. Hoje, pode-se considerar que as pesquisas e o avanço da Logística Empresarial foram abruptos e exponenciais, atingindo patamares de grande notoriedade e importância nas empresas, assumindo assim um caráter estratégico para que a organização consiga lidar com as adversidades e impor a competitividade requerida para a sua sobrevivência. De mesmo modo, a Logística Humanitária tem crescido com as corporações de apoio humanitário, atraindo o interesse de diversos países no tema (VAN WASSENHOVE, 2006).

Ao se considerar o avanço da produção intelectual em Logística Humanitária, Thomas e Kopczak (2005) alegam que as pesquisas, caso comparadas com o setor clássico da Logística no âmbito privado, estão atrasadas em 20 anos. Mesmo levando em conta essas limitações contemporâneas constatadas, pode-se notar que a Logística Humanitária começou a valorizar e a adotar conceitos já adotados pela Logística Empresarial, como enxergar as operações e atividades logísticas utilizando a perspectiva de cadeia ou rede de suprimentos, englobando todos os seus fornecedores, fabricantes e clientes, levando assim em consideração seus relacionamentos e atividades requeridas (VAN WASSENHOVE, 2006).

Ao se tratar a relação entre $L H$ e a $L E$, pode-se reparar que elas se diferem em diversos níveis. Há diferenças quando o assunto é objetivo, visto que na LH o foco é minimizar as perdas e aliviar o sofrimento dos indivíduos vulneráveis, enquanto na LE a finalidade é o aumento da qualidade e redução de custos em todos os processos, satisfazendo assim o cliente, colocando-o em primeiro lugar invariavelmente. Já em relação às incertezas e ambiente caótico, as duas se diferem, dada a necessidade repentina da LH de atender aos vulneráveis em questão, mesmo com limitações financeiras e humana, lead times necessariamente ínfimos, para assim assegurar os fluxos de suprimentos aos mais necessitados, garantindo assim os direitos humanos fundamentais. De mesmo modo, outras variáveis são consideradas tanto na LH quanto na $L E$, como os centros de distribuição, para assim providenciar os insumos requisitados e o uso de sistemas de informação, para analisar os diferentes dados coletados e, assim, fornecer o apoio necessário de maneira eficiente (NOGUEIRA; GONÇALVES; NOVAES, 2007).

Como exemplo do processo logístico humanitário e suas condições operacionais, pode-se citar, segundo Telford e Cosgrave (2006), o terremoto no Oceano Índico em dezembro de 2004, onde vários tsunamis foram criados na costa noroeste da Sumatra oriundos de um terremoto de alta magnitude. Essa série de tsunamis afetou 14 países, como Indonésia, Tailândia, Sri Lanka e Maldivas, ocasionando em 227 mil mortes e 1,7 milhão de desabrigados. A partir desse evento, a mídia se mobilizou em resposta ao desastre, atuando de forma exemplar aos Direitos Humanos e gerando uma ajuda de 13,5 bilhões de dólares em doações, amenizando assim a perda material total da região, de 9 bilhões de dólares. 
Todavia, a ajuda humanitária, quando não coordenada em questões de suprimentos, recursos monetários e pessoas, gera ineficiência e imprecisão em seus fluxos. Ainda, pôde-se notar o exagerado número de pessoas voluntárias que estavam presentes, tornando a ação humanitária mais dispendiosa, e, devido à ajuda excessiva em questões de financiamento, as organizações humanitárias se desmotivaram, reduzindo ainda mais a eficiência da operação. Por fim, os fluxos na cadeia de suprimentos humanitária foram prejudicados, visto que houve um excesso nas doações realizadas, além de algumas terem caráter inadequado para o cenário de desastre, produzindo demasiada perda de tempo no manejo e transporte (CHRISTOPLOS, 2006). Ainda, a distribuição de suprimentos foi realizada de forma aleatória, pois não havia uma lista esquematizada com os entes afetados, como pessoas e bens, resultando em problemas sérios no auxílio humanitário provenientes de problemas de gestão logística de distribuição (TELFORD; COSGRAVE, 2006).

Podem-se citar resultados ainda mais estarrecedores, como: roupas doadas abandonadas, aeroportos interditados, acesso aos portos bloqueados por carros, suprimentos indesejados, falta de pessoal treinado em ações humanitárias, roubos, perdas, comercialização das doações e dezenas de armazéns com suprimentos e bens deteriorando por fluxos assíncronos e ineficientes (GUNAWAN et al., 2015). Vale ressaltar, como exemplo desta operação humanitária, a deficiência na avaliação das necessidades das pessoas em seu local de desastre, como o levantamento pífio de registros hospitalares de pessoas da região, levando a erros médicos e inadequações de atendimentos e socorro (TELFORD; COSGRAVE, 2006).

A ajuda humanitária provém, muitas vezes, de organizações governamentais, que alcançam positivos resultados em situações de desastres a vulneráveis, auxiliando em diversas situações e salvando vidas. Há, dentre algumas organizações, a CARE , que significa cuidado em inglês, sendo criada em 1945 com a fusão de 22 organizações norte-americanas. O nome CARE teve sua origem no termo "Care Packages", que eram pacotes utilizados na Segunda Guerra Mundial com bens essenciais e alimentos e, assim, enviados para os sobreviventes por intermédio de organizações de auxílio. Números surpreendentes marcam a caminhada da organização, como a marca de ajuda humanitária em 87 países em 2010, além de atingir um total de 810 milhões de pessoas. Hoje, é considerada uma confederação internacional com 14 organizações, atuando em 94 países, e tem em sua missão salvar vidas, erradicar a pobreza e alcançar justiça social. 0 seu foco são as meninas e as mulheres, pois estes grupos são os rostos mais vulneráveis aos problemas oriundos da pobreza nas comunidades de baixa renda mundo afora, além do fato incontestável de que a capacitação do público feminino é o principal caminho para que famílias inteiras consigam sair de situações de miséria (HENRY, 1999). 
A assistência pós-desastre tem, normalmente, duas fontes. O governo, com o uso de militares ou defesa civil, e as organizações internacionais de assistência, que possuem o conhecimento e recursos para ajudar as populações afetadas por essas crises (KUNZ; REINER, 2012). No entanto, na maioria das vezes, esses desastres exigem assistência internacional, dado que a maior parte da assistência humanitária é oriunda de doações.

O descompasso entre as necessidades humanitárias globais e os recursos disponiveis, juntamente com a vulnerabilidade crônica em muitas partes do mundo, continua a ter um impacto direto na vida de milhões de pessoas que necessitam de assistência humanitária (HEASLIP, 2013). Assim, Thomas e Kopczak (2005) definem Logística Humanitária como o processo de planejar, implementar e controlar o fluxo e o armazenamento de bens e materiais, bem como a gestão das informações relacionadas, do ponto de origem até o ponto de consumo, com o objetivo de aliviar o sofrimento das pessoas vulneráveis ${ }^{1}$ . Para tanto, uma série de atividades são englobadas em sua função, incluindo preparação, planejamento, aquisição, transporte e armazenamento.

\section{A GARANTIA AO MEIO AMBIENTE SAUDÁVEL E SUA RELAÇÃO COM A LOGÍSTICA HUMANITÁRIA GREEN}

Os fenômenos naturais tais como chuvas, deslizamentos de terra, terremotos, ciclones, tsunamis, etc., apesar de serem parte da história da humanidade passaram a fazer parte da vida urbana, tendo em vista os impactos causados pelo homem no ambiente. Por este raciocínio, um desastre natural ocorre quando um desses fenômenos causa danos a uma população e/ou ao meio ambiente. Todavia, este desastre apenas se torna objeto da logística humanitária quando pessoas são atingidas (LEIRAS et al., 2017).

Nesse viés, a logística humanitária pode ser definida como "o conjunto de planejamentos e ações que visam salvar vidas, deslocar pessoas, materiais, promover o fluxo de informações e gerenciar a aquisição, armazenagem, transporte e distribuição de suprimentos para atender às pessoas atingidas por desastres" (LEIRAS et al., 2017, p. 28).

Como bem ressalta Kuijt (2015), o termo "desastre natural", no entanto, carece de uma definição nos tratados internacionais, sendo preciso recorrer às normas com caráter de soft law para conceituá-

\footnotetext{
1 Para fins do presente artigo, o termo "pessoas vulneráveis" se refere àquelas direta ou indiretamente afetadas pelo desastre. A vulnerabilidade pode ser dada em dois contextos: pessoas que já se encontram em uma situação eminente de risco, desastre ou ataque terrorista; indivíduos que já foram afetados em uma situação de pós-desastre.
} 
lo. A Resolução da ONU de n 42/169 de 11 de dezembro de 1987 inclui na expressão desastre natural passivel de ajuda humanitária os seguintes: terremotos, tempestades de vento (ciclones, furacões, tornados, tufões), tsunamis, enchentes, deslizamentos de terra, erupções vulcânicas, incêndios e outras calamidades de origem natural. Dois anos depois, a Resolução 44/236 de 22 de dezembro de 1989 incluiu nesse conceito a infestação de gafanhotos, seca e desertificação.

A Resolução de Assistência Humanitária do IFRC, por sua vez, define no rol de suas ações em prol da assistência humanitária, que o termo desastre se refere a eventos calamitosos que colocam em perigo a vida, a saúde, a integridade física ou o direito de não ser submetido a tratamentos cruéis, desumanos ou degradantes, ou outros direitos humanos fundamentais, decorrentes de fenômenos naturais (terremotos, erupções vulcânicas, vendavais, chuvas torrenciais, enchentes, deslizamentos de terra, secas, incêndios, fome, epidemias); de origem tecnológica provocados pelo homem (desastres químicos e explosões nucleares); e conflitos armados ou violentos (internacionais ou conflitos armados internos, distúrbios ou violência interna, atividades terroristas) (IFRC, 2003). Deve-se lembrar, contudo, que as operações humanitárias devem seguir os princípios da neutralidade, humanidade, imparcialidade e independência, nos termos da Resolução 46/182 da ONU (UNOCHA, 2012).

Para Kuijt (2015, p.86), a IFRC oferece uma noção bastante ampla do que seria um desastre, tendo inclusive desenvolvido diretrizes contendo um conjunto de recomendações aos governos sobre como preparar suas leis e planos de desastres para os problemas regulatórios comuns em operações internacionais de assistência em catástrofes. Essa iniciativa é inclusive apoiada pela Assembleia Geral da ONU na Resolução 63/141 de 11 de dezembro de 2008, que encoraja os Estados a segui-las.

Ao se analisar a Logística Humanitária, deve-se mencionar que respostas convencionais aos desastres naturais perturbam o meio ambiente e todos os seres que o cercam. Assim, em geral, ao se examinar as operações humanitárias em áreas críticas, pode-se afirmar que o ambiente é ainda mais danificado à medida que a maior parte das emissões de carbono atreladas às atividades logísticas se soma à saúde ambiental, já frágil, do lugar (JILANI; ALI; KHAN, 2018). Isso se dá, no passo que as respostas abruptas e fáceis a desastres naturais nunca são simples, envolvendo diversas variáveis a serem consideradas, como a emissão de poluentes oriunda do transporte de insumos como: remédios, comida e bebida às diferentes localidades afetadas, assim como o controle do seu custo total, parte essencial para o sucesso da ação humanitária e sua sustentação e conservação pelo período requisitado, dado pelo momento que os indivíduos deixarem o seu caráter de vulnerabilidade. 
Argumenta-se frequentemente, no crescente corpo de pesquisa em logística ${ }^{2}$ e gestão green ${ }^{3}$, que iniciativas ambientais fazem organizações mais eficientes ao reduzirem o uso de recursos de diferentes maneiras possíveis. Contudo, em organizações temporárias, tais como as operações humanitárias, objetivos, como o de salvar vidas, são caracterizados por alvos de curto prazo. Diante do exposto, podese dizer que nesses casos o importante é ser eficaz e conseguir bons resultados, não tendo relevância os meios utilizados para obtê-los. Por sua vez, ser eficiente é atingir resultados positivos fazendo o uso de poucos recursos, o que ainda é um desafio, visto que os processos de Logística Humanitária (LH) hoje não tem por objetivo imediato a redução dos recursos (ENG-LARSSON; VEGA, 2018).

Eventos como inundações, erupções, tsunamis, terremotos, furacões, deslizamentos de terras podem converter-se em desastres naturais quando afetam pessoas, causando, em combinação com a antropização, danos ao meio ambiente. No entanto, na prestação de auxílio humanitário, a utilização de meios de transportes com combustiveis fósseis e a distribuição de suprimentos em embalagens nãorecicláveis podem, por exemplo, acarretar na multiplicação dos danos ambientais já causados.

O terremoto ocorrido em 2004 no Oceano índico, que afetou países asiáticos e africanos; o terremoto no Haiti (nível 7 na Escala Richter), um dos países mais pobres do mundo, em 2010, no qual faleceram 316.000 pessoas, 350.000 ficaram feridas e aproximadamente 1 milhão e meio ficaram sem lar, sem contar com os milhares de deslocados ambientais; são exemplos recentes de desastres naturais objeto de preocupação da logística humanitária (LEIRAS et al., 2017, p. 92-93).

Por outro lado, desastre não natural como o acidente de Chernobyl, em abril de 1986, na cidade de Pripyat, atual Ucrânia; a fuga de gás venenoso (isocianato de metilo), em dezembro de 1984, em Bhopal, Índia, na fábrica química de pesticidas da companhia norte-americana Union Carbide causando a morte por envenenamento de aproximadamente 30.000 pessoas e o deslocamento forçado de milhares de outras, são fenômenos que afetam diretamente tanto o meio ambiente natural quando a população (TRINDADE; LEAL, 2017, p. 55) e que merecem, por conseguinte, a atenção dos estudos de logística humanitária.

A logística verde, no contexto da logística humanitária, incentiva todas as partes envolvidas a levar em consideração o impacto de suas ações no meio ambiente, tendo como objetivo reduzir tais impactos.

\footnotetext{
2 Processo de planejamento, implementação e controle do fluxo e armazenamento eficiente e de baixo custo de matérias-primas, estoques em processo, produtos acabados e informações relacionadas desde o ponto de origem até o ponto de consumo para fins de conformidade com requisitos do cliente (Council of Supply Chain Management).

${ }^{3}$ Refere-se à integração do comportamento empresarial aliado à consciência ambiental (BACKER, 2002). Além disso, exige a inclusão de considerações ambientais em todos os processos empresariais, incluindo atividades de desenvolvimento de produtos e planejamento estratégico (BARBIERI, 2004).
} 
A logística verde ou sustentável preocupa-se em reduzir os impactos redesenhando os sistemas de fornecimento / distribuição. A título exemplificativo, a embalagem de materiais representa um dos maiores desafios para uma logística ambientalmente amigável e, ao mesmo tempo, vital no transporte e armazenamento. A questão é que a embalagem correta ou incorreta gerará impactos no transporte, armazenamento e volume de materiais em um determinado espaço, além do descarte. Na esfera da logística sustentável, há uma preocupação em como recuperar, reciclar ou efetivamente descartar as embalagens (WHITE, 2015).

A questão que se chama atenção na presente pesquisa é que, por vezes, no atendimento às vítimas em desastres ambientais que impactam tanto a humanidade quando o meio ambiente, deixa-se de pensar em meios sustentáveis de promover a ajuda humanitária. Um dos poucos exemplos de união de auxílio humanitário com práticas sustentáveis foi o navio Tres Hombres4, o qual funciona apenas com energia limpa gerada por turbinas eólicas ou óleo vegetal reciclado, e partiu da Holanda em 17 de janeiro de 2010 para entregar bens humanitários oriundos de organizações holandesas ao povo do sul do Haiti. O transporte de 12 toneladas de carga humanitária se deu sem a emissão de carbono, a partir da logística green.

Nesse sentido, o navio Tres Hombres é um exemplo global de navio transatlântico ecológico a trazer ajuda humanitária para uma área de desastre ambiental que une as preocupações com direitos humanos e direito ambiental, contribuindo para a preservação do meio ambiente por meio da minimização dos impactos e atuando em prol das vítimas.

À luz do caso ora em estudo, neste contexto, Severo, Dorion e De Guimarães (2020) relatam que as barreiras do crescimento sustentável, como a mudança climática, demográfica, pobreza e escassez de recursos possibilitam organizações a empregar práticas ambientais e ações sociais que resultam em novas oportunidades de negócios. Neste passo, vale ressaltar a inovação com foco ecológico, ou ecoinovação, considerada uma nova filosofia organizacional, a qual se pode incluir os pilares da sustentabilidade (social, ambiental e econômico), denominando uma mudança de paragima. Além disso, os autores citam o crescimento da produção científica em relação à inovação com foco em sustentabilidade, o qual é reconhecido por possuir uma abordagem transdisciplinar. Cita-se, ademais, que a inovação sustentável é reconhecida igualmente por inovação verde, ecoinovação e inovação ecológica.

\footnotetext{
${ }^{4}$ Reportagem de 15 de abril de 2010 sobre o navio Tres Hombres, "Think Green in Humanitarian Logistics - The Green Vessel of the Caribbean", disponivel em: <https://logcluster.org/blog/think-green-humanitarian-logistics-\%E2\%80\%93-green-vessel-carib bean?fbclid=IwAR1tVw32S4LVJZE4Ca4giMm-IOJq5ahuPOMvxYpvgkm3HDu2q2IQ5FqFWoU>. Acesso em: 10 out. 2019.
} 


\section{A PRESERVAÇÃO DO MEIO AMBIENTE A PARTIR DA LOGÍSTICA HUMANITÁRIA GREEN: UMA ANÁLISE A PARTIR DOS PRINCIPAIS INSTRUMENTOS NORMATIVOS INTERNACIONAIS}

O direito ao meio ambiente saudável e ecologicamente equilibrado é um direito de todos garantido em diversos princípios e artigos de vários instrumentos normativos internacionais. O Direito Ambiental Internacional é, contudo, recente, tendo como marcos iniciais dois eventos globais: a Conferência das Nações Unidas sobre o Meio Ambiente Humano, realizada na Suécia (Estocolmo), em 1972, e a Conferência das Nações Unidas sobre o Meio Ambiente e Desenvolvimento, realizada no Brasil (Rio de Janeiro) em 1992 (OLIVEIRA, 2007, p. 65).

As motivações para a criação de normas e princípios voltados a preservação do meio ambiente estiveram relacionadas a alarmante degradação ambiental na segunda metade do século vinte, cuja "constatação fez surgir, ainda que gradativamente, uma nova concepção na qual se incluiu as questões ambientais a preocupação com a natureza por ela própria e não somente enquanto objeto de interesse do homem" (OLIVEIRA, 2007, p. 110).

Todavia, dada a multidimensionalidade do direito ambiental internacional, "a abordagem das questões relativas à proteção ao meio ambiente exige uma análise em conjunto com as mais diversas áreas do conhecimento, pois lida com valores e interesses que são atingidos pelas medidas tomadas para o alcance se seus objetivos" (OLIVEIRA, 2007, p. 123). Desse modo, a ciência e a tecnologia se mostram faces do direito ambiental internacional essencial para avanços na criação de instrumentos de proteção. Contudo, por outro lado esse mesmo desenvolvimento científico e tecnológico também atua como causador de dano ambiental.

Por esse motivo, não é por mera conveniência que o artigo $9^{\circ}$ da International Law Comission's Draft Articles on the Protection of Persons in the Event of Disasters de 2016 destaca o papel do Direito, por intermédio da legislação e regulamentos, na redução de riscos de desastre, juntamente com as demais áreas do conhecimento que atuam na prevenção, mitigação e preparo (CARVALHO, 2019). Nesse sentido, no que concerne ao desenvolvimento do direito dos desastres:

Nossa era é uma época marcada pelos extremos. Eventos, comportamentos, clima, acidentes, decisões. Énesse cenário e para esta conflitualidade que se forma um Direito dos Desastres, tratando-se este também de um Direito extremo, fundado sob a ideia central de que a gravidade destes eventos exige uma regulação sensivel ao risco e a incerteza. Trata-se de um Direito que chama a atenção da humanidade para a crise ambiental que se vive, enfrentando-se graves acidentes industriais, inovações tecnológicas que chegam ao consumo generalizado e de maneira cada vez mais rápida, e efeitos de uma natureza influenciada pelas mudanças climáticas (CARVALHO, 2015, p. 21). 
Jung (2017) também salienta a vinculação entre o direito ambiental e do direito dos desastres nas questões relacionadas às mudanças climáticas, que vem causando degradação ambiental e, por vezes, impactando na ocorrência de desastres naturais que podem levar ao deslocamento forçado de populações. No entanto, o chamado "direito dos desastres", ainda que careça de normatização específica, pode ser compreendido como "um conjunto de regras e noções que versam sobre a relação humano-ambiental, por conseguinte, exemplos deste conjunto são tratados internacionais, costumes e leis que, somados, constroem um pacote de medidas assessórias a uma calamidade" (JUNG, 2017, p. 91).

\subsection{MARCOS NORMATIVOS NO ÂMBITO INTERNACIONAL PARA A PRESERVAÇÃO DO MEIO AMBIENTE E REDUÇÃO DOS RISCOS DE DESASTRES NATURAIS}

A formação da concepção moderna de Direito Ambiental teve como marco normativo internacional a Declaração de Estocolmo de junho de 1972, fruto da Conferência das Nações Unidas sobre Meio Ambiente, que trouxe as discussões acerca dos desastres ambientais, risco aos recursos naturais e à biodiversidade a uma amplitude global (SAAVEDRA, 2014, p. 119-132).

De acordo com o teor da Declaração, o ser humano é ao mesmo tempo obra e construtor do meio ambiente que o cerca, o qual the dá sustento material e Ihe oferece oportunidade para desenvolverse intelectual, moral, social e espiritualmente, sendo o meio ambiente humano (o natural e o artificial) essenciais para o bem-estar do homem e para o gozo dos direitos humanos fundamentais. Verifica-se, nesse sentido, a importância da Declaração de Estocolmo para a proteção dos diretos ambientais a nível internacional.

O direito a um ambiente saudável como um direito humano está previsto como princípio primeiro da Declaração de Estocolmo, considerada o marco da proteção ambiental no âmbito dos direitos humanos. No entanto, da leitura desse princípio, não se identifica uma explícita menção ao direito a um meio ambiente saudável, não obstante o princípio primeiro enunciar de forma clara os direitos civis, políticos e econômicos, dando destaque à liberdade, à igualdade e a condições de vida dignas. Mesmo diante da inexistência de uma expressa menção ao direito a um meio ambiente saudável, a intenção da Declaração de Estocolmo é inserir a proteção ambiental como um pré-requisito para o gozo e exercício dos direitos humanos (CAMPOS, 2017, p. 31).

Na Assembleia Geral da ONU realizada em 22 de dezembro de 1989, foi aprovada a Resolução 44/236, que considerou a década de 1990 como início da Década Internacional para Redução dos Desastres Naturais (DIRDN), reconhecendo a importância da proteção ambiental para prevenção e mitigação dos desastres naturais. 
Em 1992 ocorreu a Conferência das Nações Unidades para o Meio Ambiente e o Desenvolvimento (CNUMAD), também conhecida como Rio-92 (Rio de Janeiro, de 3 a 14 de junho de 1992), sediada no Brasil. 0 documento fruto dessa conferência, a Declaração do Rio, tinha por objetivo reafirmar o comprometimento dos países com o meio ambiente saudável como um dos pilares para o gozo e exercício dos direitos humanos. Menciona-se ainda, a Convenção sobre a Diversidade Biológica, um tratado da Organização das Nações Unidas também precedente da CNUMAD que tem como pilar a conservação da diversidade biológica, o uso sustentável da biodiversidade e a utilização equitativa e justa dos recursos genéticos.

A adoção da Agenda 21, cujo intuito era a proteção dos recursos naturais do planeta e seu desenvolvimento sustentável, teve início em 1971, em Estocolmo. Em 1992, resultante da relação entre 0 meio ambiente e o desenvolvimento, tornou-se evidente a necessidade de os países tomarem iniciativas para o desenvolvimento sustentável. Desse modo, a agenda 21 propõe a adoção de várias medidas nacionais, regionais e globais para tratar dos problemas ambientais e promover o desenvolvimento sustentável, incluindo a proteção da atmosfera e da biodiversidade; a proteção dos mares e oceanos; a gestão de produtos químicos, resíduos perigosos e radioativos; questões envolvendo o combate à pobreza e controle populacional; e o papel dos trabalhadores, sindicatos, empresas, indústrias, agricultores e povos indígenas na promoção do desenvolvimento sustentável (LOUKA, 2006, p. 32-33).

Relevante mencionar ainda o Protocolo de Quioto ${ }^{5}$, um tratado complementar à Convenção-Quadro das Nações Unidas sobre Mudança do Clima, criado em 1997, que define metas de redução de emissões para os países desenvolvidos e aqueles que apresentavam economia em transição para o capitalismo. $\mathrm{E}$ a 15a Conferência das Partes (COP) ocorrida em Copenhague, na Dinamarca, em 2009 que congrega as nações signatárias da Convenção-Quadro sobre Mudança do Clima das Nações Unidas, e que também tinha por objetivo a redução e gases de efeito estufa. Fruto desses trabalhos, foi gerada uma declaração de intenções sem efeito vinculante.

Além dos encontros sediados em Estocolmo e no Rio de Janeiro, em 2002 foi sediada em Johanesburgo a Cúpula Mundial sobre Desenvolvimento Sustentável para avaliar as conquistas e desafios das novas questões surgidas desde a Cúpula da Terra de 1992. Originário dessa conferência, os EstadosMembros assinaram a Declaração sobre Desenvolvimento Sustentável e o Plano de Implementação de ações que contribuem para o desenvolvimento sustentável. Ambos os documentos têm como objetivo: a dignidade da pessoa humana; o desenvolvimento sustentável a partir dos pilares de desenvolvimento

\footnotetext{
${ }^{5}$ O Brasil ratificou o documento em 23 de agosto de 2002, tendo sua aprovação interna se dado por meio do Decreto Legislativo $n^{\circ} 144$ de 2002.
} 
econômico e social, e proteção ambiental; redução da pobreza e da desigualdade; vencer os desafios da globalização; e a criação de instituiç̧ões democráticas, efetivas e acessiveis (LOUKA, 2006, p. 35-36).

Em 2005, a ONU adotou o Marco de Ação de Hyogo, fruto da II Conferência Mundial sobre Desastres (a primeira foi realizada em 1994), cujo principal objetivo era discutir a gestão de risco de desastres a fim de aprimorar as ações destinadas a aumentar a resiliência das nações e comunidades em relação aos desastres de modo a alcançar, até 2015, uma redução das perdas provocadas por desastres, tanto relacionada às vidas humanas como também aos bens sociais, econômicos e ambientais (POZZNER, COHEN, COSTA, 2014). O Marco de Ação de Hyogo (UNISDR, 2005) tem cinco áreas tidas como prioritárias: fazer com que a redução dos riscos seja uma prioridade; conhecer o risco e adotar medidas; desenvolver uma maior compreensão e conscientização; reduzir o risco; e fortalecer a preparação em desastres para uma resposta eficaz, em todos os níveis.

Um diálogo com a preocupação em reduzir os desastres pode ser observado na conferência realizada em Nova York em setembro de 2015 - a Cúpula de Desenvolvimento Sustentável - na qual 193 Estados-membros da ONU se reuniram para definir os novos objetivos de desenvolvimento sustentável na Agenda 2030. 0 documento adotado se chama "Transformando o Nosso Mundo: A Agenda 2030 para o Desenvolvimento Sustentável" inclui 17 objetivos e 169 metas para a erradicação da pobreza, preservação do meio ambiente e garantia para as gerações futuras, ou seja, construir um mundo mais sustentável e resiliente até 2030. De acordo com o documento, é preciso que haja cooperação internacional para reforçar a resiliência das comunidades que acolhem refugiados; conscientização sobre a conservação e uso sustentável dos oceanos e mares, recursos de água doce, bem como as florestas, montanhas e terras áridas e proteger a biodiversidade, os ecossistemas e a vida selvagem, de maneira a combater a escassez de água e a poluição da água, fortalecer a cooperação sobre a desertificação, as tempestades de poeira, a degradação dos solos e a seca e promover a resiliência e a redução do risco de desastres. Destaca-se ainda, o dever de os Estados-membros de construir, até 2030, a resiliência dos pobres e daqueles em situação de vulnerabilidade, reduzindo a exposição e vulnerabilidade destes a eventos extremos relacionados com o clima e outros choques e desastres econômicos, sociais e ambientais (ONU, 2016).

Ainda, no intuito de reforçar a resiliência e a capacidade de adaptação a riscos relacionados ao clima e às catástrofes naturais, fruto da Terceira Conferência Mundial da ONU para a Redução de Riscos de Desastres, em Sendai (Japão), a Declaração de Sendai e o Marco para a Redução de Riscos de Desastres 2015-2030, cujo intuito é entender os riscos de desastres; fortalecer o gerenciamento dos riscos; investir na redução dos riscos e na resiliência; reforçar a prevenção de desastres e dar respostas efetivas, de modo a minimizar os impactos dos desastres naturais até o ano de 2030. Durante a Conferência Mundial, os Estados reiteraram seu compromisso com a redução do risco de desastres e com o aumento da 
resiliência a desastres no contexto do desenvolvimento sustentável, a partir de uma gestão eficaz dos riscos e vulnerabilidades a desastres naturais (UNISDR, 2015). De acordo com a Declaração de Sendai, há uma urgência em prever, planejar e reduzir o risco de desastres, a fim de proteger de forma mais eficaz pessoas e comunidades, bem como os ecossistemas, recursos naturais e o meio ambiente como um todo. Já no aspecto de atendimento humanitário no pós-desastre, os países devem se comprometer em buscar soluções sustentáveis e respostas eficazes, de modo a aprimorar as capacidades técnicas e logísticas, a fim de garantir uma melhor resposta em situações de emergência (UNISDR, 2015).

No atendimento humanitário, ainda deve ser levada em conta a questão dos deslocados ambientais, os quais, diferentemente de outros migrantes (como por exemplo, os refugiados) não deixam seu país de origem por vontade própria, mas em decorrência de desastres naturais (JUNG, 2017, p. 92). Nesse aspecto, embora haja uma omissão legislativa em âmbito internacional quanto a tutela dos deslocados ambientais forçados "externos", o Alto Comissariado das Nações Unidas para os Refugiados (ACNUR), em 2007, abandonou o princípio da neutralidade ao assumir o a função de protegê-los, o que tornou-se ainda mais evidente com a publicação Climate Change, Natural Disasters and Human Displacement: a UNHCR Perspective em 2008, e também em 2010 com a publicação Earth, wind and fire. A review of UNHCR's role in recent natural disasters (LUCHINO, RIBEIRO, 2016, p. 897-900).

O Relatório Mundial sobre Desastres do IFRC dos anos 2000 observou que há uma falta de organização e abrangência jurídica nos instrumentos normativos internacionais relacionados à resposta a desastres. Por esse motivo, em virtude da ausência, até então, de um tratado internacional contendo os mecanismos legais aplicáveis aos desastres naturais, em 2001, a Federação Internacional das Sociedades da Cruz Vermelha e do Crescente (IFRC) convidou o Professor Horst Fischer da Ruhr-Universität Bochum para examinar os principais tratados internacionais relacionados à resposta a desastres internacionais e identificar pontos em comum, diferenças e lacunas em mais de 130 instrumentos normativos internacionais (FISCHER, 2003). Do resultado, o projeto denominado International Disaster Response Law (IDRL) tem a principal tarefa de reduzir a vulnerabilidade e sofrimento das pessoas afetadas por desastres, sejam naturais ou tecnológicos, a partir da promoção de mecanismos legais que facilitem uma assistência humanitária internacional mais efetiva.

Para o professor Horst Fischer "a principal tarefa da ajuda humanitária é resgatar as vítimas de desastres naturais, emergências e conflitos armados e garantir sua sobrevivência" (FISCHER, 1998, tradução nossa). Nesse contexto, as Operações Europeias de Proteção Civil e de Ajuda Humanitária (European Civil Protection and Humanitarian Aid Operations - ECHO) se dispõem a salvaguardar a integridade e a dignidade daqueles afetados por desastres naturais e crises provocadas pelo ser humano. 
Percebe-se, portanto, que no cenário internacional muitos instrumentos normativos foram criados para a promoção da resiliência do direito ambiental, principalmente por meio de ações que visam a educação ambiental e da logística humanitária, a partir do desenvolvimento de ações que contribuem para a preservação do meio ambiente até mesmo após catástrofes ambientais. Ainda assim, a construção de um direito ao meio ambiente saudável como um direito humano fundamental na ajuda humanitária pós-desastre ainda se mostra um desafio no âmbito global, especialmente no que concerne às medidas tomadas no pós-desastre. A união, nesse sentido, da garantia aos direitos humanos por meio da ajuda humanitária em desastres, a preocupação com o meio ambiente na logística humanitária através de práticas sustentáveis, mostra-se um instrumento eficaz e capaz de concretizar os princípios do direito ambiental internacional em concomitante com a garantia dos direitos humanos.

\subsection{A RESPONSABILIDADE INTERNACIONAL POR DESASTRES NÃO NATURAIS}

Não obstante os elogios à Declaração de Estocolmo e a Declaração Rio, ainda era preciso um instrumento normativo em âmbito internacional que atribuísse responsabilidade aos agentes responsáveis por desastres não naturais que impactam gravemente tanto o meio ambiente quanto a população. Nesse contexto, um grande exemplo está na explosão seguida de incêndio e libertação de radioatividade em Chernobyl em 1986, cujos impactos chamaram a atenção para a necessidade de prevenção de desastres com consequências devastadoras para a saúde das pessoas e a integridade dos ecossistemas, bem como serviram de imperativo de responsabilização nas esferas civil e penal dos seus agentes causadores do dano ambiental (TRINDADE; LEAL, 2017, p. 55).

Nesse viés, em 1998 foi assinado o Estatuto de Roma, o qual criou o Tribunal Penal Internacional (TPI) e estabeleceu os crimes sobre os quais é competente para julgar um Estado. Dentre o rol desses crimes, consta na classificação "crimes de guerra" a conduta de lançar intencionalmente um ataque, sabendo que o mesmo causará perdas acidentais de vidas humanas ou ferimentos na população civil, danos em bens de caráter civil ou prejuízos extensos, duradouros e graves no meio ambiente que se revelem claramente excessivos em relação à vantagem militar global concreta e direta que se previa.

Todavia, o âmbito de responsabilização penal por esta conduta perante o TPI ainda encontrase bastante restrito, tendo em vista que tão somente desastres artificiais com dolo evidentemente comprovado se encontrariam nessa conduta e não a mera omissão de organizações em tomar as devidas precauções para evitar um desastre ambiental. Nesse sentido, "a restrição do âmbito de aplicação do crime de dano ambiental a "crimes de guerra" é muito limitativa, mas não exclui por completo a possibilidade de um atentado grave a componentes ambientais constituir crime - mesmo que a degradação provocada não configure o bem jurídico protegido pela norma" (GOMES, 2017, p. 67). 
As situações de dano ambiental passíveis de tipificação como crime internacional contra o meio ambiente são, entretanto, de difícil verificação, seja porque normalmente se enquadram como crimes de guerra, ou porque envolvem a violação dos direitos humanos, exigindo, para qualificação do crime acima mencionado, o preenchimento cumulativo de um conjunto de requisitos dotados de alto grau de subjetividade:

\begin{abstract}
Casos como a catástrofe socioambiental da bacia do Níger provocada pela poluição descontrolada produzida nas refinarias da Shell lançada para as águas, agudizada a partir da década de 1990; ou como a descarga, em 2006, de mais de quinhentas toneladas de resíduos altamente tóxicos pela Trafigura Lda em dezoito locais dos arredores de Abidjan, gerando mortes, um enorme alarme sanitário e poluição duradoura no solo e na água, são exemplos de "willful blindness", de uma 'indiferença consciente' das empresas relativamente aos efeitos das suas ações, pontuais ou sistemáticas, e dos modelos de funcionamento que desenvolvem. Mas não cabem, objectivamente, nos tipos desenhados no Estatuto de Roma (GOMES, 2017, p.73).
\end{abstract}

Embora o sistema jurídico desempenhe um papel fundamental na prevenção, resposta e gestão de desastres, os desastres frequentemente são causados ou agravados por falhas na proteção ambiental. Nesse contexto, Farber (2011, p. 1783-1785), ao estabelecer relações convergentes entre o direito ambiental e o direito dos desastres, salienta que a falta de regulação ambiental pode atuar como agente potencializador de desastres ambientais. Atitudes como ocupação irregular do solo, contaminações em larga escala, desrespeito às áreas proteção ambiental, podem contribuir para a ocorrência de desastres, ainda que de forma gradual e lenta. Por isso, em muitos casos, os desastres podem ser resultados de falhas na regulamentação ambiental. Nesse contexto, Farber (2011, p. 1797-1798) cita como exemplos o desastre industrial provocado pelo derramamento de óleo no Golfo do México em 2010, cujas consequências ecológicas foram devastadoras; e o nevoeiro letal de 1952, em Londres, fruto da poluição atmosférica.

De acordo com a International Commission on Intervention and State Sovereignty (ICISS), dentre o rol de situaç̃̃es que configuram entre 'justa causa' para intervenção militar, estão as "'catástrofes naturais ou ambientais avassaladoras, quando o Estado em causa não deseja ou é incapaz de lidar com, ou pede ajuda, e ameaça ou efetiva perda significativa de vidas (EVANS; SAHNOUN, 2001, p.33, tradução nossa)", e também aqueles crimes contra a humanidade definidos nas Convenções e Protocolos Adicionais de Genebra. $O$ documento elaborado em 2001 pela ICISS expõe a doutrina da responsabilidade em proteger ("R2P"), segundo a qual, quando um Estado deixa de proteger seu povo - seja por falta de capacidade ou de vontade - a responsabilidade recai na comunidade internacional. 
Nesse contexto, consoante Trascasas (2012, p. 235), o Secretário-Geral da ONU aponta como razão para excluir a aplicação da doutrina da responsabilidade de proteger (The Responsability to Protect) a 'outras calamidades como HIV-AIDS, mudanças climáticas ou a resposta a desastres naturais' por considerar que uma interpretação mais ampla deste conceito poderia prejudicar as políticas existentes apoiar e tornar sua implementação mais difícil. Desse modo, a aplicação dessa doutrina está restrita àqueles quatro crimes (genocídio, crimes de guerra, limpeza étnica e crimes contra a humanidade), em relação aos quais há um consenso na comunidade internacional.

A implementação da doutrina "R2P" foi colocada em pauta numa consulta ao G20 pela Federação Internacional da Cruz Vermelha e das Sociedades do Crescente Vermelho em 2009 (IFRC, 2009), onde a maioria dos governos reconheceu a responsabilidade primária das autoridades nacionais em dar respostas aos desastres naturais. Uma postura mais flexível foi exposta pelo Canadá e no atendimento aos afetados por desastres naturais. Tão somente os Estados Unidos apoiaram expressamente a doutrina ao reconhecer que, diante da incapacidade ou falta de ação dos governos locais de proteger seus próprios cidadãos, deve ser tomada uma ação internacional, cujo posicionamento foi confirmado logo após a crise do ciclone Nargis em Mianmar em 2008 (TRASCASAS, 2012, p. 236).

Alguns desastres naturais ou tecnológicos acarretam em consequências graves que podem restringir os direitos e liberdades individuais a uma extensão incompativel com as obrigações internacionais do país no ramo dos direitos humanos. Nesse sentido, diante de um desastre, as respostas legais e governamentais para o atendimento às vítimas, com o propósito fundado na mitigação dos riscos de agravamento da situação e no momento de tomada de decisões em situações de emergência, devem ser levadas em consideração a necessidade de se evitar maiores danos ao meio ambiente do que aqueles já ocasionados pela catástrofe ambiental. Desse modo, as ações relacionadas à logística humanitária no pós-desastre precisam ser voltadas ao futuro, a garantia do meio ambiente saudável para as próximas gerações, visando atender a perspectiva internacional de preservação ambiental e os princípios de direito ambiental universais previstos nos diversos instrumentos normativos internacionais.

As temáticas envolvendo o Direito Ambiental e os Direitos Humanos precisam ser vistas sob a ótica da resiliência como um processo de garantia de preservação do meio ambiente. De acordo com Silva (2015, p.37), a importância de se estudar o conceito de resiliência ambiental reside na interdependência e inter-relação entre os seres humanos e o meio ambiente, como parte de seu conteúdo, sendo que este é dependente dos recursos providos pelo meio ambiente e atua como gestor de sua preservação, o qual Ihe traz a responsabilidade de comprometer-se com a sobrevivência da humanidade. 


\section{CONSIDERAÇÕES FINAIS}

O reconhecimento do direito fundamental ao meio ambiente saudável se mostra uma interface entre Direitos Humanos e proteção ambiental, requerendo ações e planos interdisciplinares para sua concretização. Nesse âmbito, no que concerne a garantia desse direito quando diante de um desastre ambiental (seja natural ou provocado pelo homem), as ações relacionadas à ajuda humanitária, principalmente no transporte e doação de mantimentos às vítimas, precisam versar sobre meios sustentáveis que não causem maiores impactos ambientais do que aqueles já existentes. A título exemplificativo, a utilização do navio Tres Hombres, com energia limpa, para o transporte de doações e mantimentos à população atingida pelo terremoto no Haiti em 2010, mostrou-se uma iniciativa em prol da preservação do meio ambiente, evitando maiores impactos ambientais.

O desenvolvimento de práticas sustentáveis na logística humanitária se mostra um imperativo à manutenção do direito ao meio ambiente saudável, principalmente nos momentos de ajuda humanitária em catástrofes ambientais. Desse modo, a união da logística humanitária com a gestão green permite dar maior concretude aos princípios internacionais de preservação ambiental previstos em diversos instrumentos normativos, tais como a Declaração de Estocolmo e a Declaração do Rio. As atividades de logística e transporte foram identificadas como tendo um grande impacto no meio ambiente, atraindo significativa atenção da legislação em nivel internacional a partir do estabelecimento de metas pela comunidade internacional para melhorar o desempenho ambiental.

Por fim, verificou-se que o desenvolvimento da logística humanitária na perspectiva sustentável e ambiental se mostra um meio eficiente de garantir o meio ambiente saudável como um direito humano fundamental. Todavia, observa-se a necessidade de aprofundar as pesquisas sobre Logística Humanitária green, com vistas a elucidar os gaps atuais de pesquisa, provenientes de um cenário de elevada complexidade, onde danos em múltiplos níveis decorrem da negligência das organizações perante questões ambientais.

\section{REFERÊNCIAS}

BACKER, P. Gestão ambiental: a administração verde. Rio de Janeiro: Qualitymark, 2002.

BARBIERI, J.C. Environmental Management: Concepts, Models and Tools. São Paulo: Saraiva, 2004.

BARTOLINI, Giulio; NATOLI, Tommaso. Disaster Risk Reduction: an International Law perspec-

tive. Questions of International Law. 2018. Disponivel em: <http://www.qil-qdi.org/disaster-risk-reduction-international-law-perspective/>. Acesso em: 24 ago. 2018. 
CAMPOS, Bárbara Pincowsca Cardoso; MUCHAGATA, Márcia. Direitos humanos e meio ambiente: avanços e contradições do modelo de desenvolvimento sustentável brasileiro e a agenda internacional. In: TRINDADE, Antõnio Augusto Cançado; LEAL, César Barros (Ed.). Direitos humanos e meio ambiente. [s.l.] Expressão Gráfica e Editora, 2017.

CARVALHO, Délton Winter de. As mudanças climáticas e a formação do direito dos desastres. Novos Estudos Jurídicos, 18(3), 397-415, 2013.

CARVALHO, Délton Winter de. Desastres ambientais e sua regulação jurídica: deveres de prevenção, resposta e compensação ambiental. São Paulo: Editora dos Tribunais, 2015.

CARVALHO, Délton Winter de. A formação do dever internacional de redução de riscos de desastres. Revista Consultor Jurídico, 10 de março de 2019. Disponivel em: <https://www.conjur.com.br/ 2019-mar-10/delton-winter-dever-internacional-reducao-riscos-desastres\#_ftn8>. Acesso em: 24 ago. 2020 .

CHRISTOPLOS, Ian. Links between relief, rehabilitation and development in the tsunami response: $\mathrm{A}$ synthesis of initial findings. Tsunami Evaluation Coalition (TEC), 2006.

ENG-LARSSON, F.; VEGA, D. Green Logistics in Temporary Organizations: A Paradox? Learnings from the Humanitarian Context. Supply Chain Forum: An International Journal, v. 12, n. 2, p. 128-139, 2018.

EVANS, Gareth J.; SAHNOUN, Mohamed. The responsibility to protect: report of the International Commission on Intervention and State Sovereignty. IDRC, 2001. Disponível em: <https://www.idrc.ca/en/ book/responsibility-protect-report-international-commission-intervention-and-state-sovereignty>. Acesso em: 21 ago. 2020.

FARBER, Daniel. Navigating the intersection of environmental law and disaster law. BYU Law Review, v. 2011, n. 6, 1783-1820, 2011.

FISCHER, Horst. International Law and Humanitarian Assistence. In: FISCHER, Horst, ORAA, J. (Eds.) International Law and Humanitarian Assistance. Brussel: European Communities, 1-145, 1998.

FISCHER, Horst. International disaster response law treaties: trends, patterns and lacunae. In: IFRC, International Disaster Response Laws, Principles and Practice: reflections, prospects, and challenges. International Federation of the Red Cross and Red Crescent Societies, Geneva, 24-44, 2003.

GOMES, Carla Amado. Ambiente e crimes contra a paz e segurança da humanidade. In: TRINDADE, Antõnio Augusto Canç ado; LEAL, César Barros (Ed.). Direitos humanos e meio ambiente. Expressão Gráfica e Editora, 2017. 
GONÇALVES, M. B.; LIMA, F. S. a Logística Humanitária no contexto da pesquisa, ensino e extensão universitária. Revista Gestão \& Sustentabilidade Ambiental, v. 7, p. 19, 2018.

GUNAWAN, Iwan et.al. City Risk Diagnostic for Urban Resilience in Indonesia. Jakarta: World Bank, 2015. Disponivel em: <https://openknowledge.worldbank.org/handle/10986/23771>. Acesso em: 17 ago. 2020.

HEASLIP, G. Services operations management and humanitarian logistics. Journal of Humanitarian Logistics and Supply Chain Management, v. 3, n. 1, p. 37-51, 2013.

HENRY, Kevin M. CARE International: Evolving to Meet the Challenges of the 21st Century. Nonprofit and Voluntary Sector Quarterly, v. 28, n. 109, 1999.

IFRC, International Federation of Red Cross and Red Crescent Societies. History. Disponivel em: http:// www.ifrc.org/en/who-we-are/history. Acesso em: 09 jun. 2019.

IFRC, International Federation of Red Cross and Red Crescent Societies. Centre for Research on the Epidemiology of Disasters. World disasters report 2000. International Federation of Red Cross and Red Crescent Societies, 2000. Disponivel em: <https://www.ifrc.org/Global/Publications/disasters/WDR/ 9000-WDR2000.pdf>. Acesso em: 17 ago. 2020.

IFRC, International Federation of Red Cross and Red Crescent Societies. Humanitarian Assistance. Institute Of International Law: Bruges Session, 2003. Disponivel em: <https://www.ifrc.org/Docs/idrl/I318EN. pdf>. Acesso em: 18 ago. 2020.

IFRC, International Federation of Red Cross and Red Crescent Societies. Believe in Humanity: Consultation with G20 governments. Novembro, 2009. Disponivel em: <http://www.ifrc.org/Global/Publications/ volunteers/G20_Consultation_Report_

Nov2009.pdf>. Acesso em: 22 ago. 2020.

IFRC, International Federation of Red Cross and Red Crescent Societies. Humanitarian logistics and procurement. 2014. Disponivel em: <https:/www.ifrc.org/es/introduccion/logistics/>. Acesso em: 17 ago. 2020.

IFRC, International Federation of Red Cross and Red Crescent Societies. World Disaster Report. 2016. Disponível em: <https:/www.ifrc.org/Global/Documents/Secretariat/201610/WDR\%202016-FINAL_web.pdf>. Acesso em: 17 ago. 2020. 
JILANI, A.; ALI, Y.; KHAN, M. W. Greening of humanitarian supply chain with focus on logistics. International Journal of Business Performance and Supply Chain Modelling, v. 10, n. 1, p. 49-66, 2018.

JUNG, Pedro Ernesto Neubarth. "Deslocados Ambientais" e os Desastres. Revista Gestão e Desenvolvimento, v. 14, n. 2, p. 88-98, 2017.

KOVÁCS, G.; SPENS, K. Humanitarian Logistics in Disaster Relief Operations, International Journal of Physical Distribution \& Logistics Management, v. 37, n. 2, p. 99 - 114, 2007.

KOVACS, G.; SPENS, K. M. Trends and developments in humanitarian logistics - a gap analysis. International Journal of Physical Distribution \& Logistics Management, v. 41, n. 1, p. 32-45, 2011.

KUNZ, Nathan; REINER, Gerald. A meta analysis of humanitarian logistics research. Journal of Humanitarian Logistics and Supply Chain Management, 2012.

KUIJT, Emilie Ellen. Humanitarian assistance and state Soveriegnty in international law: towards a comprehensive framework. Doctoral Thesis, Leiden University. Cambridge: Intersentia, 2015. Disponível em: <https://openaccess.leidenuniv.nl/handle/1887/36434>. Acesso em: 19 ago. 2020.

LEIRAS, Adriana et al. Logística Humanitária. [s.l.] Elsevier Brasil, 2017.

LOUKA, Elli. International Environmental Law: Fairness, Effectiveness, and World Order. Cambridge University Press, 2006.

LUCHINO, María Mercedes Rodríguez Fontán; RIBEIRO, Wagner Costa. Refugiados ambientais e a atuação do ACNUR como organismo internacional de proteção. Revista Eletrônica do Curso de Direito da UFSM, 11.3: 890-914, 2016.

NOGUEIRA, C. W.; GONÇALVES, M. B.; NOVAES. A. G. Logística Humanitária e Logística Empresarial: Relações, Conceitos e Desafios. In: ANPET. Anuário Nacional de Pesquisa e Ensino em Transportes 2007. Rio de Janeiro: 2007.

OLIVEIRA, Rafael Santos de Oliveira. Direito Ambiental Internacional: o papel da soft law em sua efetivação. ljuí: Editora Unijuí, 2007.

ONU. Organização das Nações Unidas. Transformando o nosso mundo: a Agenda 2030 para o Desenvolvimento Sustentável. 2016. Traduzido pelo Centro de Informação das Nações Unidas para o Brasil (UNIC Rio), última edição em 25 de setembro de 2015. Disponivel em: <https://sustainabledevelopment. un.org>. Acesso em: 11 out. 2019. 
ONU. Organização das Nações Unidas. Resolução 41/169 - Década Internacional para Redução de Desastres Naturais. 11 de dezembro de 1987. Disponível em: <https:/undocs.org/en/A/RES/42/169>. Acesso em: 17 ago. 2020.

ONU. Organização das Nações Unidas. Resolução 63/141. 11 de dezembro de 2008. Disponível em: <https://undocs.org/en/A/RES/63/141>. Acesso em: 17 ago. 2020.

ONU. Organização das Nações Unidas. Draft articles on the protection of persons in the event of disasters. 2016. Disponivel em: <https://legal.un.org/ilc/texts/instruments/english/draft_articles/6_3_2016.pdf>. Acesso em: 22 ago. 2020.

ONU. Organização das Nações Unidas. Estatuto de Roma. Aprovado em 17 de julho de 1998 pela Conferência Diplomática de Plenipotenciários das Nações Unidas sobre o estabelecimento de um Tribunal Penal Internacional. Roma, 1998.

POZZER, Camila Pinheiro; COHEN, Simone C.; COSTA, Francisco da Silva. O Marco de Ação de Hyogo aplicado à gestão de risco de inundação no Brasil e em Portugal. Territorium, n. 21, p. 49-70, 2014.

SAAVEDRA, Fernando Estenssoro. História do debate ambiental na política mundial: 1945-1992. Tradução Daniel Rubens Cenci. ljuí: Editora Unijuí, 2014.

SEVERO, Eliana Andréa; DORION, Eric Charles Henri; DE GUIMARÃES, Julio Cesar Ferro. Hélices Holísticas de Inovação e Ecoinovação: Drivers para o desenvolvimento Sustentável. Revista Gestão e Desenvolvimento, v. 17, n. 2, p. 57-81, 2020.

SIBLEY, Adam. World Summit on Sustainable Development (WSSD): Johannesburg, South Africa. Encyclopedia of earth. Washington, DC: Environmental Information Coalition, National Council for Science and the Environment. Last revised: October, 2007.

SILVA, Andresa Tatiana da. Resiliência e os direitos difusos e coletivos ao meio ambiente equilibrado. 2015. 115 f. Orientador: Prof. Me. Paulo Affonso Leme Machado Dissertação (mestrado) - Universidade Metodista de Piracicaba, Direito, 2015.

TELFORD, John; COSGRAVE, John. Joint evaluation of the international response to the Indian Ocean tsunami: Synthesis report. Tsunami Evaluation Coalition (TEC), 2006.

THOMAS, Anisya S.; KOPCZAK, Laura Rock. From logistics to supply chain management: the path forward in the humanitarian sector. Fritz Institute, v. 15, p. 1-15, 2005. 
TRASCASAS, Milena Costas. Access to the Territory of a Disaster-Affected State. In: International Disaster Response Law. TMC Asser Press, The Hague, The Netherlands, p. 221-249, 2012.

TRINDADE, Antonio Augusto Cançado; LEAL, César Barros. Direitos Humanos e Meio Ambiente. Fortaleza: Expressão Gráfica e Editora, 2017.

UNISDR. International Strategy for Disaster Reduction. 2015. Sendai Framework for Disaster Risk Reduction 2015 - 2030. Disponível em: <http://www.preventionweb.net/files/43291_sendaiframeworkfordrren.pdf>. Acesso em: 15 set. 2019.

UNISDR. Escritório das Nações Unidas para a Redução do Risco de Desastres. Marco de Ação de Hyogo 2005-2015: Aumento da resiliência das nações e das comunidades frente aos desastres. Traduzido por Luís Felipe Lopes de Lima Lins Departamento de Minimização de Desastres, Secretaria Nacional de Defesa Civil. 2005.

UNOCHA. United Nations Office for the Coordination of Humanitarian Affairs. Humanitarian Principles. June, 2012. Disponivel em: <https:/www.unocha.org/sites/dms/Documents/OOM-humanitarianprinciples_eng_June12.pdf >. Acesso em: 17 ago. 2020.

VAN WASSENHOVE, Luk N. Humanitarian aid logistics: supply chain management in high gear. Journal of the Operational research Society, v. 57, n. 5, p. 475-489, 2006.

WHITE, Justin. Green Logistics. Logistics Operational Guide (LOG), 10 de agosto de 2015. Disponivel em: <https://dlca.logcluster.org/display/LOG/Green+Logistics>. Acesso em: 10 set. 2019. 